\title{
Role of Interstitial Branching in the Development of Visual Corticocortical Connections: A Time-Lapse and Fixed-Tissue Analysis
}

\author{
Edward S. Ruthazer ${ }^{1}$, Amelia R. Bachleda ${ }^{2}$, and Jaime F. Olavarriaa ${ }^{3,}$ \\ ${ }^{1}$ Montreal Neurological Institute, McGill University, Montréal, Québec, H3A 2B4 Canada \\ ${ }^{2}$ Biological and Biomedical Sciences Program, University of North Carolina, Chapel Hill, North \\ Carolina 27599-7108 \\ ${ }^{3}$ Department of Psychology, University of Washington, Seattle, Washington 98195-1525
}

\section{Abstract}

\begin{abstract}
We combined fixed-tissue and time-lapse analyses to investigate the axonal branching phenomena underlying the development of topographically organized ipsilateral projections from area 17 to area 18a in the rat. These complementary approaches allowed us to relate static, large-scale information provided by traditional fixed-tissue analysis to highly dynamic, local, small-scale branching phenomena observed with two-photon time-lapse microscopy in acute slices of visual cortex. Our fixed-tissue data revealed that labeled area 17 fibers invaded area 18a gray matter at topographically restricted sites, reaching superficial layers in significant numbers by postnatal day 6 (P6). Moreover, most parental axons gave rise to only one or occasionally a small number of closely spaced interstitial branches beneath 18a. Our time-lapse data showed that many filopodium-like branches emerged along parental axons in white matter or deep layers in area 18a. Most of these filopo-dial branches were transient, often disappearing after several minutes to hours of exploratory extension and retraction. These dynamic behaviors decreased significantly from $\mathrm{P} 4$, when the projection is first forming, through the second postnatal week, suggesting that the expression of, or sensitivity to, cortical cues promoting new branch addition in the white matter is developmentally down-regulated coincident with gray matter innervation. Together, these data demonstrate that the development of topographically organized corticocortical projections in rats involves extensive exploratory branching along parental axons and invasion of cortex by only a small number of interstitial branches, rather than the widespread innervation of superficial cortical layers by an initially exuberant population of branches.
\end{abstract}

\section{INDEXING TERMS}

visual cortex; corticocortical; imaging; motility; two-photon; time lapse

\begin{abstract}
In the cerebral cortex, a hierarchy of topographically interconnected cortical areas processes information relayed by sensory systems. Previous studies in many species have argued that the mature patterns of corticocortical connections develop from widespread neonatal distributions of projection neurons (Wise and Jones, 1976; Innocenti et al., 1977). In contrast, at early stages of development, most anterogradely labeled axons are restricted to
\end{abstract}

(C) 2010 Wiley-Liss, Inc.

*CORRESPONDENCE TO: Jaime F. Olavarria, Department of Psychology, University of Washington, Box 351525, Seattle, WA 98195-1525. jaime@uw.edu. 
white matter and appear to invade gray matter only in those cortical regions where they are found in the adult (Olavarria and Van Sluyters, 1985; Aggoun-Zouaoui and Innocenti, 1994; Kennedy et al., 1994; Caric and Price, 1996; Barone et al., 1996; for review see Innocenti and Price, 2005). In rodents, studies of the development of the interhemispheric callosal pathway show that parental axons navigate through white matter or lower cortical layers, often growing past their targets, and give rise to interstitial branches that extend toward the pia in regions that are callosally innervated in adults (Hogan and Berman, 1990; Fish et al., 1991; Norris and Kalil, 1992; Hedin-Pereira et al., 1999; Ding and Elberger, 2001; Olavarria and Safaeian, 2006). Similar observations have been made in studies of ipsilateral corticocortical connections in the cat (Kennedy et al., 1994; Caric and Price, 1996) and monkey (Barone et al., 1996).

However, little is known about the details of the process by which organized topography develops in corticocortical connections. At present, it is unclear whether the growth of interstitial branches and elaboration of axon arbors in gray matter is precise from the start or whether an extensive remodeling process is required for the establishment of topography within corticocortical target regions. A recent study found that the topography of corticocortical callosal connections in rats neonatally enucleated by postnatal day 4 (P4) is markedly different from that in normal animals even from the onset of cortical innervation. These findings provide evidence that early enucleation leads to abnormal corticocortical maps not by interfering with a remodeling process but by altering topographic cues guiding the invasion of interstitial axon branches into gray matter (Olavarria and Safaeian, 2006).

Previous work, based solely on the analysis of fixed tissue, does not provide the temporal and spatial resolution that is needed for a detailed description of local, dynamic processes that may occur during map formation. Recent studies incorporating living tissue and highresolution time-lapse imaging techniques have revealed dynamic processes that appear to play an important role in the developmental remodeling of dendrites, dendritic spines, and axons, including the addition or retraction of many more branches and filopodia than are evident at any single time point (O'Rourke et al., 1994; Dunaevsky et al., 1999; Lendvai et al., 2000; Cline, 2001; Tashiro et al., 2003; Ruthazer et al, 2003; Majewska and Sur, 2003; Hua et al., 2005; Knott et al., 2006; Portera-Cailliau et al, 2005). However, in vivo timelapse imaging of axons growing deep in the cortex or in white matter is not currently practical.

We therefore set out to study the development of projections from area 17 to ipsilateral area 18a using two-photon time-lapse imaging in acute slices of the rat visual cortex (Halloran and Kalil, 1994; Bastmeyer and O'Leary, 1996). To assess early topographic mapping, we first performed a quantitative analysis in fixed tissue of the distribution and topography of interstitial branches in area 18a following injections of anterograde tracers into area 17 of neonatal rats. Our two-pronged analysis suggests that the frequency of small filopodium-like processes exploring white matter decreases with age as the projection map forms and that only one or a small fraction of these many fine branches will ultimately lead to a stable projection that innervates the overlying gray matter. Abstracts of these results have been presented previously (Olavarria et al., 2003, 2006).

\section{MATERIALS AND METHODS}

Our study is based on data obtained from first- and second-postnatal-week rat pups. Pregnant rats were monitored several times daily, and the births of the litters were determined to within 12 hours. The first 24 hours are considered P0. All surgical procedures were performed according to protocols approved by the Institutional Animal Care and Use 
Committees at the University of Washington and the Montreal Neurological Institute of McGill University.

\section{Axon labeling for live imaging}

In area 18a of adult rats, a 2-mm-wide strip of cortex adjacent to the lateral border of area 17 (see Fig. 1) contains several separate representations of the visual field, each of which maintains retinotopically organized connections with area 17 (e.g., areas AL, LM, PL, P; Montero et al., 1973; Olavarria and Montero, 1984; Coogan and Burkhalter, 1993). A common feature of the maps in these areas is that the azimuthal axis is represented as a compressed mirror image of its representation in V1 (Montero et al., 1973; Olavarria and Montero, 1981, 1984; Coogan and Burkhalter, 1993). Axonal projections from area 17 to area 18a were labeled in vivo with the fluorescent tracers AlexaFluor 488 dextran or AlexaFluor 594 dextran (Invitrogen; 5\% w/v in 0.1 M phosphate buffer). Pups (up to P7) were anesthetized by hypothermia, and small injections of the tracer (total volume of about $0.01 \mu \mathrm{l}$ ) were placed into presumptive area 17, at about $0.5 \mathrm{~mm}$ anterior to the lambda suture and $3.0 \mathrm{~mm}$ from the midline. The topographical location of the injection site in area 17 was confirmed by analyzing the position of the labeling field in ipsilateral dorsal lateral geniculate nucleus (dLGN; Fig. 1D). Furthermore, because the dLGN does not project to secondary visual areas in the rat cortex, the presence of labeling in the dLGN is evidence for accurate targeting of the injection into area 17. In pups, area 17 extends about $3.5 \mathrm{~mm}$ from the midline (unpublished observations), so injections close to the lateral border of area 17 minimize the distance between the origin and the termination of the neural projection, increasing the chances that both the soma and the growing axon of labeled cells are contained in the same coronal slice. However, we cannot rule out the possibility that some of the axons that we studied were severed during slice preparation because we were not always able to follow the axons to the cells of the origin because of the intense brightness of the fluorescent tracer near the injection site. A previous study in vivo reported that retinal axons that were severed by removing the retina continued to grow for periods of many hours (Harris et al., 1987), suggesting that severed axons contain the machinery responsible for their dynamic behavior.

\section{Acute slice preparation}

One or more days after the dextran injections, P4-7 pups were deeply anesthetized by hypothermia, whereas pups older than P7 were anesthetized by inhalation of isoflurane. As described previously (Olavarria et al., 2007), occipital cortical blocks were rapidly resected, glued to the stage of a vibrating microtome (Leica), and immersed in ice-cold "cutting" solution composed of (in mM): $5 \mathrm{KCl}, 1.25 \mathrm{KH}_{2} \mathrm{PO}_{4}, 26 \mathrm{NaHCO}_{3}, 5 \mathrm{MgCl}_{2}, 20$ TEA-Cl, 105 choline- $\mathrm{Cl}, 20$ sucrose, and 10 dextrose (pH 7.2; $320 \mathrm{mOsm})$. Coronal slices (300 $\mu \mathrm{m}$ thick) from the visual cortex (see Fig. 1B, C) were cut and transferred into a chamber filled with artificial cerebrospinal fluid (ACSF) and kept at $35^{\circ} \mathrm{C}$ for 1 hour. The ACSF contained (in $\mathrm{mM}$ ): $130 \mathrm{NaCl}, 3 \mathrm{KCl}, 2 \mathrm{CaCl}_{2}, 1.25 \mathrm{NaH}_{2} \mathrm{PO}_{4}, 26 \mathrm{NaHCO}_{3}, 2 \mathrm{MgCl}_{2}$, and 10 dextrose and was kept at $\mathrm{pH} 7.3-7.4$ by bubbling with a $5 \% \mathrm{CO}_{2} / 95 \% \mathrm{O}_{2}$ mixture. After this initial period, the slices were kept at room temperature until use.

\section{Time-lapse imaging}

Brain slices were submerged in a chamber mounted on a fixed stage of an Olympus BX61WI microscope and perfused continuously with carbogenated ACSF $\left(36^{\circ} \mathrm{C}\right)$ flowing at a rate of 3-4 ml/min. Time-lapse images of axons labeled with fluorescent dextrans were acquired using Fluoview (Olympus) software and a custom-modified two-photon laser scanning microscope with an Olympus $\times 40(0.8 \mathrm{NA})$ or $\times 60(0.9 \mathrm{NA})$ water immersion lens. Labeled axons in deep cortical layers or in white matter were imaged at 2 to 60-minute intervals for periods ranging from 20 minutes to 8 hours. This allowed us to document the 
branch dynamics at different temporal resolutions, but for relatively short observation periods. In experiments in which we investigated the developmental regulation of branch dynamics, we used intervals of 10 minutes or less. At the end of most imaging sessions, lowpower (10×, $0.25 \mathrm{NA}$ air objective) brightfield and fluorescence images were taken to record the depth and position of the imaged field in the slice.

At each time point, a z-series at $1-\mu \mathrm{m}$ intervals was collected. At this resolution, the parental axon of emerging branches could be identified unambiguously. Side branches measuring 2 $\mu \mathrm{m}$ or more in length were analyzed. The dynamic remodeling of the axon arbors was measured by quantifying the loss and gain of identified side branches from each individual arbor from one observation to the next using custom macros for Object Image software (Ruthazer and Cline, 2002). Digital images of the primary axon and of axon branches were drawn by hand at each observation time point, and the resulting drawings were carefully superimposed for all observations. The primary axon and each branch were identified and measured separately. The data were entered into Excel spread sheets and analyzed by using custom macros. Parameters analyzed included rate of branch addition or elimination per length of the primary axon per hour, cumulative growth and retractions rates, orientation of branch (e.g., toward white matter or gray matter), rate of growth or retraction for individual branches, lifetimes and age-related changes in branch density and dynamics. In total, 79 axons from rat pups aged between $\mathrm{P} 4$ and P12 were analyzed.

\section{Axon labeling for fixed-tissue analysis}

Tracer injections were made in animals anesthetized either by hypothermia or with halothane (0.5-1.5\% in air). Biotinylated dextran amine (BDA; $10 \%$ in DW; Molecular Probes, Eugene, OR) was used to perform a large-scale analysis of the distribution of interstitial branches in area 18a of 22 pups ranging in ages from P3 to P9. Single, small injections of BDA $(\sim 0.01 \mu \mathrm{l})$ were placed in presumptive area 17, at a distance of 2.8-3.5 $\mathrm{mm}$ from the midline and about $0.5 \mathrm{~mm}$ anterior to the lambda suture. To study the development of topography in the 17-18a projection, small injections of AlexaFluor 488 and Alexa-Fluor 594 dextrans (5\% w/v in $0.1 \mathrm{M}$ phosphate buffer) were made into different mediolateral loci (separated by 300-700 $\mu \mathrm{m}$ ) in area 17 in three pups at P5. For all tracers, the topographic location of the injection sites in area 17 was confirmed by analyzing the position of the retrogradely labeled field in ipsilateral dLGN. Both BDA and Alexa dextran tracers were pressure injected through glass micropipettes (50-100 $\mu \mathrm{m}$ tip diameter). The pipette containing the tracers was lowered to about $600-800 \mu \mathrm{m}$, and about 1 minute after the injection it was slowly retracted. All injections analyzed were restricted to the gray matter. In determining the ages for injecting and perfusing the animals, we assumed that the pattern of connections revealed with BDA and Alexa dextran is that present at the time of perfusion (Simon and O'Leary, 1992).

\section{Histochemical processing}

After a 24-48-hour survival time, the animals were deeply anesthetized with pentobarbital sodium $(100 \mathrm{mg} / \mathrm{kg}$ i.p.) and perfused through the heart with $0.9 \%$ saline followed by $4 \%$ paraformaldehyde in $0.1 \mathrm{M}$ phosphate buffer ( $\mathrm{PB} ; \mathrm{pH}$ 7.4). The brains were removed and those injected with BDA were left overnight in $30 \%$ sucrose and $0.1 \mathrm{M} \mathrm{PB}$. The BDA data were analyzed in series of $80-\mu \mathrm{m}$-thick coronal sections obtained using a freezing microtome. BDA labeling was revealed using the standard avidin-biotin-peroxidase protocol (Vectastain Elite ABC kit; Vector, Burlingame, CA) and $0.01 \% \mathrm{H}_{2} \mathrm{O}_{2}$ in $0.05 \% 3,3^{\prime}-$ diaminobenzidine, with cobalt or nickel intensification; sections were then mounted, dehydrated, defatted, and coverslipped. Brains injected with Alexas were sectioned in the coronal plane (100- $\mu \mathrm{m}$-thick sections) using a vibrating microtome (Leica). After being mounted and coverslipped with Vectashield (Vector) as the mounting medium, these 
sections were analyzed and photographed at $\times 20$ (0.25 NA air) using an Axiovert epifluorescent microscope (Zeiss) equipped with a digital camera (Optronics).

\section{Data acquisition and analysis}

Patterns of BDA-labeled fibers were analyzed using a microscope equipped with a motorized stage (LEPCO) controlled by a Dell XPS T500 computer and a graphic system (Neurolucida; MicroBrightField, Williston, VT). The location of the injection sites in presumptive area 17 was determined by estimating the location of this area in Nissl-stained sections. However, because the lesions produced by the injections often made it difficult to analyze local cytoarchitectonic patterns, a more reliable way to assess the location of the tracer injections was provided by the analysis of the distribution of anterogradely labeled fields within the ipsilateral dLGN (see Fig. 2A, B; Montero et al., 1968; Godement et al., 1979; Warton et al., 1988).

Sections taken from the injected hemisphere were examined, and one or more sections passing through the center of the injections were photographed to illustrate the location and size of the tracer deposits (see Fig. 2A). Histological sections passing through areas of highest labeling density were selected for detailed analysis of the distribution of anterograde fiber labeling, and some of these sections were used to illustrate the results obtained. To estimate the location and number of branches that originated from individual parental axon segments at P6, we examined the cortex lying between the injection site and the termination zone in area 18a and drew (40x, $0.85 \mathrm{NA}$ air) the parental axon segments that we observed in lower cortical layers and white matter as well as the interstitial branches that emerged from them. We considered only branches that could easily be distinguished $(>10 \mu \mathrm{m}$ in length) and that unambiguously originated from axons coursing mediolaterally. When more than one branch originated from a single parental axon segment, the distance between these branches was measured. Finally, we counted the number of branches that emerged from single parental axon segments. These segments were divided into three groups measuring $100-300 \mu \mathrm{m}, 301-500 \mu \mathrm{m}$, and 501-800 $\mu \mathrm{m}$ in length. Figures were prepared in Adobe Photoshop CS2, and all image processing used, including contrast enhancement and intensity level adjustments, was applied to the entire image and never locally.

\section{RESULTS}

Corticocortical projection neurons in primary visual cortex (area 17) extend their axons ventrally into the white matter, where they turn and join parallel tracts to run either in a lateral direction in the case of projections to secondary visual areas including area $18 \mathrm{a}$ or medially in the case of interhemispheric callosal projections. In the adult rat, projections from area 17 innervate area 18a in a topographically organized fashion (Montero et al., 1973; Olavarria and Montero, 1981, 1984; Coogan and Burkhalter, 1993). Although occasionally axons will cross between cortical areas without first exiting the gray matter, the vast majority of interarea corticocortical projections from area 17 are made by axons that first travel some distance through the subcortical white matter before axons or branches enter cortical targets in extrastriate areas. This raises the question of whether, during development, corticocortical axons in the white matter branch to grow precisely toward their adult targets or exhibit initial exuberance in cortical innervation sites followed by elimination of mistargeted interstitial axon branches.

\section{Histological reconstruction and analysis of corticocortical axons}

We designed anatomical experiments to analyze the distribution of relatively long interstitial branches in area 18a following discrete injections of BDA into area 17 of neonatal rats (Fig. 1). Our objectives were to obtain information about the timing of gray matter invasion by 
interstitial branches, the precision of this invasion, and the development of corticocortical topography. We placed injections of BDA into area 17 in pups at ages P1 $(\mathrm{n}=2), \mathrm{P} 2(\mathrm{n}=2)$, P3 $(n=2)$, P4 ( $=9)$, P6 $(n=4)$, and P7 $(n=3)$, which were perfused at P3, P4, P5, P6, P8, and $\mathrm{P} 9$, respectively. Although a contingent of labeled fibers was present in white matter below area 18a at P3, we observed only a few, short fibers invading deep aspects of the gray matter. By P5, a few longer fibers extended to layer 5 and occasionally up to the cortical plate from which layers 2 and 3 will differentiate (data not shown). Many of these fibers originated at right angles from parental axons that continued their mediolateral trajectory in white matter or deep cortical layers without turning into gray matter. These observations are similar to previous studies in rodents showing that interhemispheric callosal fibers often form as interstitial branches from parental axons navigating in white matter or deep cortical layers (Norris and Kalil, 1992; Hedin-Pereira et al., 1999; Ding and Elberger, 2001; Olavarria and Safaeian, 2006). The progressive ingrowth of fibers into area 18a closely paralleled the cytoarchitectural differentiation of the cortical layers from the dense cortical plate. At P6, when all cortical layers have differentiated from the cortical plate (Ignacio et al., 1995), radially oriented fibers of simple architecture extended to supragranular layers in area $18 \mathrm{a}$, often reaching layers 1 and 2.

To assess the density and precision with which axon branches invade upper cortical layers, we analyzed the distribution of BDA-labeled fibers in area 18a in P6 and P8 pups.

Comparison of the labeling pattern observed in P6 (Fig. 2A, B) animals with that observed at P8 (Fig. 3A) and in adult rats (Fig. 3B; Olavarria and Montero, 1984; Coogan and Burkhalter, 1993) shows that the density of labeled fibers is significantly lower in P6 pups, suggesting that both the number of fibers innervating area 18a and their arborization patterns are still very immature at this age (Dong et al., 2004). However, analysis of the distribution of labeled fibers in area 18a following a single, small injection of BDA into area 17 revealed that a distinct termination zone could be identified in 18a as early as P6 and that the invasion of interstitial fibers was focused to a narrow cortical column (Fig. 2A, B). Analysis of the branch distributions at P6 of area 17-to-18a projecting axons from nine rats injected with $\mathrm{BDA}$ at $\mathrm{P} 4$ was performed by reconstructing the segments of labeled axons in histological sections that included the innervation zone (Fig. 2C, D). The top panel in Figure 2C illustrates the distribution of parental axon segments with one or more collateral branches. Analysis of 189 branches emerging from 136 axon segments of different lengths shows that the number of branches emerging from the same parental axon is low $(1.39 \pm 0.067$ branches per axon). Because many of the parental axon segments analyzed in a histological section were relatively short, we were concerned that the low number of branches observed could be an artifact of the large fraction of short parental segments. However, parental axon segment length did not appear to impact this finding. The bottom panel in Figure $2 \mathrm{C}$ shows that, regardless of the length of the parental axon segment, the distribution is strongly skewed in favor of those axons with just one or two branches extending from them. Segments measuring $100-300 \mu \mathrm{m}(\mathrm{N}=93)$ had only $1.2 \pm 0.065$ branches that innervated the gray matter per axon. The number of branches from longer segments of 301-500 $\mu \mathrm{m}(\mathrm{N}=37)$ in length was slightly but not significantly greater $(1.5 \pm 0.14 ; P>0.05$, Kruskal Wallis test), providing evidence that measurements of branch number were not likely to have been impacted by parental axon length. A small number of segments measuring 501-800 $\mu \mathrm{m}(\mathrm{N}=$ 6) could be reconstructed, from which an average of $2.3 \pm 0.61$ branches emerged. This was significantly greater than the number of branches on shorter segments $(P<0.01$ vs. $100-300$ $\mu \mathrm{m}$ group, $P<0.05$ vs. 301-500 $\mu \mathrm{m}$ group, Kruskal-Wallis with Dunn posttest), raising the possibility that these axonal segments might have given off branches innervating multiple target zones within several adjacent extrastriate areas.

The few cases in which multiple branches emerged from a single parental axon can provide further clues regarding whether a small, early population of exuberant branches could 
account for plasticity in the projection map. We measured the distance between neighboring branches in parental axon segments of different lengths having more than one branch (top panel in Fig. 2D). The mean distance between neighboring branches ( $\mathrm{N}=49$ measurements) was only $83.6 \pm 8.21 \mu \mathrm{m}$, consistent with the idea that when axons emit multiple interstitial branches these tend to be closely spatially clustered. The bottom panel in Figure 2D illustrates that length of the parental axon segment again had no impact on this finding, insofar as interbranch distances of $50 \mu \mathrm{m}$ were observed in $70.8 \%$ of axons measuring $100-300 \mu \mathrm{m}, 52.9 \%$ of axons measuring $301-500 \mu \mathrm{m}$, and $62.5 \%$ of axons measuring 501$800 \mu \mathrm{m}\left(P=0.93, \chi^{2}\right.$ test $)$. The proportion of axons with branches separated by distances greater than $150 \mu \mathrm{m}$ was low $(10.2 \%)$.

These results provide evidence that only one or a few collateral branches are found on single parental axons in area 18a, and, when more than one branch does occur on single axons, these branches tend to be closely spaced. These data suggest that discrete termination zones in area 18a form by the initial extension of interstitial branches at correct places rather than by extensive elimination of exuberant or mistargeted branches. In a small percentage of measurements $(4.1 \%)$, we did find that the distance between neighboring emerging branches was as high as $250 \mu \mathrm{m}$ (Fig. 2D), but we could not trace pairs of these branches to determine whether or not they converged to the same terminal region as they extended toward the pia (see, e.g., Hedin-Pereira et al., 1999).

We also studied older animals to determine whether subsequent growth of the projection and elaboration of terminal arbors might temporarily degrade the relatively focused innervation pattern that we observed at P6. In animals injected at P6 and P7 and studied at P8 and P9, respectively $(n=7)$, we found that a restricted injection of BDA into area 17 always produced a well-defined termination zone in area 18a (Figs. 3A, 4F), similar to that observed in adult animals (Fig. 3B), arguing that the map is unlikely to be degraded by further growth at any point during development.

\section{Double-fluorescent injections: development of topography}

Data from pups injected with BDA indicate that there is progressive growth of fibers into gray matter, with a significant number of fibers reaching superficial layers by P6. Moreover, BDA data show that ingrowth of collateral branches is narrowly focused to a column within the cortex, suggesting that the invasion of fibers into gray matter occurs at well-defined topographic sites. To study the topography of the 17-18a projection just as growing fibers reach superficial layers of area 18a, we made paired injections of two differently colored fluorescent tracers into area 17 at P4 and studied the distribution of labeled fibers in 18a at P6. Figure 4A-E shows the results obtained in an animal in which the area 17 injections of AlexaFluor 488- and AlexaFluor 594-conjugated dextrans were separated by $350 \mu \mathrm{m}$ in the mediolateral direction. Low-magnification images of the injection sites and area 18a projections as they appear in the same section labeled with both tracers are shown in Figure 4A (Alexa 594) and C (Alexa 488). Higher magnification views of area 18a projections labeled with each tracer are shown in Figure 4B, D, respectively. A drawing of the data in this single section is shown in the upper panel in Figure 4E, and a reconstruction of the data in this section and in two additional neighboring sections is shown in the bottom panel of Figure 4E. The projection pattern in area 18a shows that the labeled fields form a mirror image of the injection sites with respect to the 17/18a border, as has been described for adult rats (Montero et al., 1973; Olavarria and Montero, 1981, 1984; Coogan and Burkhalter, 1993). Similar results were obtained in two other P6 animals injected at P4 with the same combination of fluorescent dextrans. These data show that the topography of striateextrastriate projections can be demonstrated as early as P6, just as growing fibers reach superficial cortical layers in area 18a. These experiments provide further evidence that 
development of area 17-18a topography does not require large-scale pruning of incorrectly placed branches in the cortical gray matter. These observations were also confirmed in experiments in which single BDA injections were systematically placed into different loci within area 17. Figure 4F shows data from three animals injected at P6 and studied at P8. In this figure, coronal sections from these three animals show injection of BDA into area 17 and the resulting labeled field in area 18a (marked with an asterisk). These data again show mirror-image topography of 17 to $18 \mathrm{a}$ projections: as the injection site is displaced medially in area 17, the projection field in area 18a is displaced laterally (Montero et al., 1973; Olavarria and Montero, 1981, 1984; Coogan and Burkhalter, 1993).

\section{Time-lapse analysis reveals many dynamic interstitial processes within the white matter}

The finding that corticocortical axons from area 17 appear to invade area 18a by emitting a single or small number of closely spaced collateral branches rather than by an exuberant invasion of side branches raises the question of how cortical axons can achieve such precise targeting of their termination zones. To examine the mechanisms controlling branching, we carried out time-lapse imaging of corticocortical axons in the white matter during the period when corticocortical axon branch formation takes place.

In vivo time-lapse imaging of deep cortical structures and white matter in the intact animal is not currently practical. In an attempt to observe axon branching events as they occurred in live cortical tissue, we performed two-photon time-lapse imaging of developing axons in acute slices of visual cortex. These slices were prepared at P4-P12 from animals that had received discrete injections of fluorescent tracers (AlexaFluor 488-or AlexaFluor 594conjugated dextrans) into area 17 at P3-P6 (Fig. 1). As in the anatomical studies described above, accurate targeting of the injection within area 17 was confirmed by analyzing the position of the retrogradely labeled field of thalamic relay neurons in the ipsilateral dLGN (Fig. 1D).

A striking feature observed in the majority of fluorescently labeled axons in young rat pups was the dense distribution of highly dynamic, fine, filopodium-like, interstitial branches on the parental axons in the white matter. These filopodial branches ranged in length from 2.0 $\mu \mathrm{m}$ (the minimum length to be considered for analysis) to $40.9 \mu \mathrm{m}$, but the large majority measured less than $10 \mu \mathrm{m}$ (mean length $3.54 \mu \mathrm{m}$ ). To investigate whether filopodial branches might represent sites of active axonal exploration within the white matter, highmagnification time-lapse images of the interstitial processes were collected along axons at intervals ranging from 2 to 60 minutes (in most cases 10 minutes) for periods ranging from 20 minutes up to 8 hours. Most of these processes exhibited surprisingly high rates of motility and turnover. Figure 5 shows two corticortical axons extending tangentially within the white matter in a P5 rat pup. Numerous interstitial processes were observed along the entire imaged lengths of both axons. The majority of these processes were extremely dynamic, some extending to reach over $10 \mu \mathrm{m}$ in length and others so short-lived as to be present during only a single image acquisition. However, a few were relatively stable and endured for all or most of the 2.5 hours of imaging. These observations suggest the possibility that exploratory interstitial branching in the white matter could be a mechanism leading ultimately to branch invasion of the overlying cortical gray matter and elaboration of terminal arbors.

\section{Dynamics of white matter interstitial axon branches decline with age}

To determine whether the dynamics of small branches emerging from parental axons in deep cortical layers or white matter are developmentally regulated, we measured the rates of interstitial branch formation and elimination in slices made from visual cortex of rat pups between the ages of P4 and P12 (Fig. 6A-D). The rates of new process addition and process 
elimination indeed showed a steady and significant decrease during the first 2 post-natal weeks (Fig. 6E). The most dynamic group of branches, transient branches (i.e., newly formed branches that were subsequently eliminated during the imaging session), were also less prevalent in older animals (Fig. 6E). Interestingly, the rate of branch addition was similar to the rate of branch elimination at each age. These dynamic branch behaviors would therefore be insufficient to drive a large cumulative expansion of the arbor but instead appear to constitute continuous transient probing by the axon.

Although there was a decline in the rate of overall interstitial branch dynamics with age, those branches that continued to exhibit dynamic behaviors in older animals elongated and retracted at the same speeds as in younger animals (Fig. 6F). This observation suggests that axonal growth and branching dynamics may be independently regulated. In addition, normally extending growth cones could be seen on many axon terminals at all ages studied and particularly in the gray matter in older animals, confirming that age-dependent differences in dynamic behaviors could not be attributed to an adverse affect of the slicing process in older animals (data not shown). The distribution of transient branch lifetimes was also constant across all age groups measured (Fig. 6G). Thus, only a decline with age in the rate of occurrence of interstitial branch addition and elimination was observed. The fact that branch dynamics decline dramatically toward the age when the patterns of corticocortical projections appear adult-like (Olavarria and Van Sluyters, 1985; Olavarria and Safaeian, 2006) is consistent with the idea that that dynamic interstitial branching may play a role in the development of organized corticocortical connections. Occasionally, we were able to image parental axons in white matter with long, perpendicular branches oriented toward the pia. When the data came from older animals, it was often apparent that filopodial activity was greater in distal portions of the branch than along the parental axon coursing in white matter (Fig. 7). This delayed filopodial activity in gray matter suggests that higher order branches making up terminal arbors in gray matter may form by mechanisms similar to those operating on parental axons in white matter.

\section{Overall interstitial axon branch density decreases with age}

Our anatomical analysis of fixed tissue revealed that only a few interstitial branches ultimately invade the superficial cortical gray matter. On the other hand, our time-lapse analysis demonstrated that the rates of branch addition and elimination both decline together with age (Fig. 6E). This analysis was not sensitive enough to reveal significant differences in the relative rates of branch formation vs. branch elimination at each age. However, based on our fixed tissue analysis, we would predict a gradual decline in the overall number of dynamic interstitial branches as the projection matures. We therefore quantified the density of interstitial branches along primary corticocortical axons in the white matter and deep cortical layers observed at different developmental stages. In the youngest animals (P4-5), interstitial processes were observed at relatively high density $(7.38 \pm 2.7$ per $100 \mu \mathrm{m}$ of parental axon length; Fig. 8A, E). Although similar interstitial extensions could be observed at all the ages studied, their density along the parental axon indeed decreased progressively with age after P5 (Fig. 8B-E; $P<0.05$, P4-5 vs. P6-12). By P10-12, interstitial branch density had decreased to just $1.34 \pm 0.43$ per $100 \mu \mathrm{m}$ of parental axon (Fig. 8D, E).

\section{DISCUSSION}

We used a combination of fixed-tissue and two-photon time-lapse approaches to relate large-scale views of the development of striate-extrastriate projections to highly dynamic, small-scale branching phenomena in white matter. With fixed-tissue preparations, we observed that parental axons gave rise to either one or a few closely spaced, interstitial branches $(>10 \mu \mathrm{m}$ in length) invading the termination zone in area 18a. In contrast, our two- 
photon, time-lapse observations revealed that many highly dynamic filopodia (mean length $3.54 \mu \mathrm{m}$ ) emerged along parental axons coursing in white matter or lower layers of area 18a. This dynamic behavior decreased progressively after $\mathrm{P} 4$, concomitant with the development of termination zones in area 18a. Together, these observations provide new insights into the mechanisms that likely underlie the development of corticocortical connections in rodents.

Filopodia-like branches were not frequently observed in our BDA material, which was obtained from brains perfused with $4 \%$ paraformaldehyde (see Materials and Methods). It is expected that most filopodia would not be evident in the single "snapshot" provided by fixed material because of their short lifetimes. Furthermore, these fine processes might have not survived the fixation protocol that we used. Indeed, we observed that most filopodia in the imaged slices could not be located after the slices were fast fixed by immersion in $4 \%$ paraformaldehyde at the end of the time-lapse imaging sessions. On the other hand, previous studies using different fixation protocols have described "hairlike" or "thornlike" filopodia measuring less than $10 \mu \mathrm{m}$ along developing geniculocortical axons in the hamster (Naegele et al., 1988). Insofar as our results from fixed tissue were obtained from branches measuring more than $10 \mu \mathrm{m}$ in length, our conclusions would not have differed even if our BDA material had preserved filopodia less than $10 \mu \mathrm{m}$ in length.

Our results show that, although area 18a is not invaded by an exuberant population of collateral branches emanating from area 17 parental axons, these parental axons do, however, exhibit a kind of "dynamic exuberance" in the form of numerous, transient filopodial processes, which may be able to detect and potentially respond to topographic cues within the subcortical white matter. This exuberance of fine processes immediately below the target structure may be what permits precise corticocortical projections to form without necessitating dramatic branch pruning in the vicinity of the termination zone. Our findings thus give rise to the following questions. What is the role of dynamic interstitial branch behavior, and what are potential mechanisms regulating it? How does precise topographic innervation of gray matter result from parental axons exhibiting multiple dynamic filopodia?

\section{Interstitial branch dynamics in cortical white matter: possible roles and regulatory mechanisms}

In one of the first descriptions of the dynamics of interstitial branching in cortical axons, Bastmeyer and O'Leary (1996) argued that filopodium-like extensions preceded the formation of major interstitial collaterals. More recently, multiphoton in vivo imaging of axons in layer 1 of somatosensory cortex has also shown that fine, dynamic process formation along axons is one of the principal modes of axonal elaboration (Portera-Cailliau et al, 2005). Moreover, in these two previous studies, as in our experiments, the rate of dynamic extensions along cortical axons was observed to decline over development. Dynamic, interstitial filopodia may probe the environment, potentially facilitating contact and communication with other cells in the vicinity bearing topographic information or providing a substrate for axonal growth, such as radial glia (Norris and Kalil, 1991), subplate neurons (Friauf et al., 1990; Kanold et al., 2003), or the corticofugal axons of the overlying cortical plate. Alternatively it may simply constitute an early phase of immature interstitial branch formation.

Although we observed a gradual decrease in the rate of white matter branch dynamics during the first postnatal week, it is equally significant that we did not observe any changes in the mean lifetimes of transient branches or in the velocity of extension and retraction of side branches during this same period. Taken together, these results implicate mechanisms controlling branch induction, rather than branch stabilization or axonal motility, as the major factors responsible for regulating the time course of corti-cocortical projection formation. 
Three distinct mechanisms could underlie the developmental down-regulation of the dynamic behavior of interstitial branches on corticocortical axons. First, the axons could have an intrinsic clock that gradually down-regulates the rate of branch initiation in synchrony with other key developmental events. An example of such intrinsic regulation is the late developmental onset of sensitivity in Xenopus retinal growth cones (RGCs) axons to the growth cone-collapsing cue Sema3a, which matures on schedule even when RGCs are cultured in isolation (Campbell et al., 2001). A second possible mechanism would be regulation of branching in response to a target-derived cue that is either up- or downregulated with age (Sato et al., 1994). Several such branch-regulating cues have been described. For example, in vitro, netrin-1 and fibroblast growth factor- 2 have been shown to promote interstitial branch formation in cortical axons, whereas Sema3a inhibits branching (Dent et al., 2004). A third possibility consistent with our data is that any of the multiple interstitial filopodial processes might potentially become the main collateral that will ultimately innervate the termination zone. In response to local topographic cues (see below), one of these processes would grow more than the others, and, upon significant extension into the gray matter, this leading branch might generate a signal that would suppress filopodial branching in the rest of the parental axon. A mechanism such as this would permit only one or occasionally a few branches to enter the overlying gray matter. This suppressive signal could be cell-autonomously generated, much as occurs during the establishment of neuronal polarity in vitro, when only one neurite is allowed by the cell to become an axon (Bradke and Dotti, 2000), or could be generated in response to a ligand located in the cortical plate, leading to the propagation of the signal throughout the rest of the cell.

\section{Precise topographic innervation of gray matter emerges from parental axons exhibiting multiple dynamic filopidia}

There is a widely held view that the initial targeting of axons and the elaboration of terminal arbors in the central nervous system are imprecise and that topographic precision is achieved through the activity-dependent, corrective removal of axon branches located in inappropriate places combined with axon branch elaboration at appropriate places (Katz and Shatz, 1996). For example, in the rodent retinocollicular projection, an initially diffuse, non-topographic elaboration of axon branches has been described, which is thought to be refined during the first postnatal week in response to a combination of molecular cues and patterned retinal activity (Simon and O'Leary, 1992; McLaughlin et al., 2003). However, we did not find evidence to support a comparable exuberant innervation of the cortex in our fixed-tissue analysis. Instead, we found that the initial invasion of fibers originating from a single, small injection of BDA in area 17 was focused and that a distinct termination zone could be identified in area 18a as early as P6. Moreover, our results show that parental axons commonly gave rise to a single interstitial branch in area $18 \mathrm{a}$, and, when more than one branch originated from one axon, these tended to be close to each other. A similar result was obtained by Olavarria and Safaeian (2006) in their study of the development of visual callosal maps in rat visual cortex. From the observation of a low proportion of neurons double labeled in striate cortex by contralateral injections of two tracers placed close to each other, these authors concluded that callosal axons in white matter give raise to only one or a few interstitial branches that invade the correct cortical target. Observations consistent with these results have been described from studies with anterograde tracers to analyze the development of callosal connections in the hamster (Fish et al., 1991; Hedin-Pereira et al., 1999).

To obtain additional, direct evidence on the development of topography, we analyzed the distribution of labeled fibers in area 18a resulting from separate injections of two anterogradely transported fluorescent tracers in area 17 . These data show that the topography of striate-extrastriate projections described in adults (Montero et al., 1973; 
Olavarria and Montero, 1981, 1984; Coogan and Burkhalter, 1993) can be demonstrated as early as P6, just as growing fibers reach superficial cortical layers in area 18a, confirming that the cortical ingrowth of interstitial fibers is topographically ordered. Our results are in agreement with a recent fixed-tissue study showing that the normal callosal map is evident by P6-7, when growing callosal fibers just reach superficial layers of area 17 (Olavarria and Safaeian, 2006). Similarly, Caric and Price (1996) observed in neonatal cats that injections of two different tracers into area 17 yielded topographically segregated projections to superficial layers of ipsilateral area 18. These results therefore do not support the idea that retinal input guides corticocortical map formation by primarily promoting the large-scale elimination of extensive, topographically disorganized branches and arbors. In the context of our time-lapse observations, these fixed-tissue data suggest that, from a population of highly dynamic interstitial branches, topographic cues somehow mediate the selection and growth of only one or a few, presumably those located at the correct topographic sites.

The extent to which our conclusions in the rat apply to the development of organized corticocortical projections in other species, such as cats and monkeys, is uncertain. In cats, transient axonal branch exuberance in white matter and layer 6 in both visual callosal (Aggoun-Zouaoui and Innocenti, 1994) and area 17 to 18 (Caric and Price, 1996) projections has been described with tract tracing anatomical methods. At first sight, it may seem that exuberance in white matter and layers 6 observed in cats during the first postnatal weeks may correspond to the transient filopodial activity that we observed in white matter and lower cortical layers in the rat. However, it is important to emphasize that we have described activity of small filopodium-like branches (mean length $3.54 \mu \mathrm{m}$ ), which were detected using high-resolution time-lapse methods, whereras, in the cat, exuberant branches measuring up to several millimeters in length (Aggoun-Zouaoui and Innocenti, 1994) were described with traditional anatomical methods in fixed tissue. Resolving this issue may require performing high-resolution time-lapse studies of the development of corticocortical projections in cats and other species in order to characterize dynamic phenomena in white matter and lower cortical layers and to determine the role that branch addition and elimination may play in the development of organized corticocortical connections.

\section{Regulation of branch dynamics and specification of corticocortical maps}

Previous studies have shown that enucleation at P4 or earlier leads to the development of abnormal interhemi-spheric projection maps, whereas enucleation at P6 or later leads to the development of normal maps (Olavarria and Hiroi, 2003; Olavarria and Safaeian, 2006). Our time-lapse observations show that the rates of branch addition and elimination, as well as the density of small branches, are high at $\mathrm{P} 4$ and subsequently decline with a similar time course, reaching their lowest values as the corticocortical projection matures in subsequent days. Therefore, dynamic branches, at least in the ipsilateral corticocortical projection, not only are present but also are most active prior to the time when the topographic callosal projection map becomes specified. Thus, the distribution of dynamic branches in very young animals may be viewed as a palette from which normal or abnormal patterns of innervation may be induced depending on whether normal or abnormal topographic cues are active during this critical period. As development proceeds, extrinsic topographic cues may bias the cytoskeletal processes underlying dynamic behavior at specific places such that one or a few closely spaced processes would be induced to grow more than neighboring processes. In corticocortical projections in normal animals, the topographic modulation of branching could be specified both by local mapping cues, such as the graded expression patterns of ephrinA (Cang et al., 2005), and by cues from the eyes, in the form of either patterned neural activity (Ruthazer et al., 2003; Cang et al., 2008) or thalamic afferent-derived molecular signals (Sugiyama et al., 2008). 
In conclusion, our time-lapse and fixed-tissue data suggest that, from the array of small dynamic branches typically found on any one parental axon, only one or a few of these located at the topographically appropriate locations will go on to grow toward the pia and ramify throughout the overlying cortex. A crucial future step toward understanding the development of cortical projection maps will be the identification of topographic cues and growth-regulating signals, whether chemical or activity-dependent in nature, that underlie the selection and growth of branches beneath their topographically correct cortical targets.

\section{Acknowledgments}

Grant sponsor: National Institutes of Health; Grant number: EY016045 (to J.F.O.); Grant sponsors: Canadian Institutes of Health Research (to E.S.R.), Canadian Foundation for Innovation (to E.S.R.), Royalty Research Fund award, University of Washington (to J.F.O.).

The authors thank Prof. Hollis Cline for support and useful discussions during the initial phase of this project, Mr. Kirill Satanovsky for assisting with axon reconstructions, and Ms. Yasuko Fujiike for assisting with analysis of BDA material.

\section{LITERATURE CITED}

Aggoun-Zouaoui D, Innocenti GM. Juvenile visual callosal axons in kittens display origin- and faterelated morphology and distribution of arbors. Eur J Neurosci. 1994; 6:1846-1863. [PubMed: 7704296]

Barone P, Dehay C, Berland M, Kennedy H. Role of directed growth and target selection in the formation of cortical pathways: prenatal development of the projection of area V2 to area V4 in the monkey. J Comp Neurol. 1996; 374:1-20. [PubMed: 8891943]

Bastmeyer M, O’Leary DDM. Dynamics of target recognition by interstitial axon branching along developing cortical axons. J Neurosci. 1996; 16:1450-1459. [PubMed: 8778296]

Bradke F, Dotti CG. Differentiated neurons retain the capacity to generate axons from dendrites. Curr Biol. 2000; 10:1467-1470. [PubMed: 11102812]

Campbell DS, Regan AG, Lopez JS, Tannahill D, Harris WA, Holt CE. Semaphorin 3A elicits stagedependent collapse, turning, and branching in Xenopus retinal growth cones. J Neurosci. 2001; 21:8538-8547. [PubMed: 11606642]

Cang J, Kaneko M, Yamada J, Woods G, Stryker MP, Feldheim DA. Ephrin-As guide the formation of functional maps in the visual cortex. Neuron. 2005; 48:577-589. [PubMed: 16301175]

Cang J, Wang L, Stryker MP, Feldheim DA. Roles of ephrin-As and structured activity in the development of functional maps in the superior colliculus. J Neurosci. 2008; 28:11015-11023. [PubMed: 18945909]

Caric D, Price DJ. The organization of visual corticocortical connections in early postnatal kittens. Neuroscience. 1996; 73:817-829. [PubMed: 8809801]

Cline HT. Dendritic arbor development and synaptogenesis. Curr Opin Neurobiol. 2001; 11:118-126. [PubMed: 11179881]

Coogan TA, Burkhalter A. Hierarchical organization of areas in rat visual cortex. J Neurosci. 1993; 13:3749-3772. [PubMed: 7690066]

Dent EW, Barnes AM, Tang F, Kalil K. Netrin-1 and semaphorin 3A promote or inhibit cortical axon branching, respectively, by reorganization of the cytoskeleton. J Neurosci. 2004; 24:3002-3012. [PubMed: 15044539]

Ding S-L, Elberger AJ. Postnatal development of biotinylated dextran amine-labeled corpus callosum axons projecting from the visual and auditory cortices to the visual cortex of the rat. Exp Brain Res. 2001; 136:179-193. [PubMed: 11206280]

Dong H, Wang Q, Valkova K, Gonchar Y, Burkhalter A. Experience-dependent development of feedforward and feedback circuits between lower and higher areas of mouse visual cortex. Vis Res. 2004; 44:3389-3400. [PubMed: 15536007] 
Dunaevsky A, Tashiro A, Majewska A, Mason CA, Yuste R. Developmental regulation of spine motility in mammalian CNS. Proc Natl Acad Sci U S A. 1999; 96:13438-13443. [PubMed: 10557339]

Fish SE, Rhoades RW, Bennett-Clarke CA, Figley B, Mooney RD. Organization, development and enucleation-induced alterations in the visual callosal projection of the hamster: single axon tracing with Phaseolus vulgaris leucoagglutinin and Di-I. Eur J Neurosci. 1991; 3:1255-1270. [PubMed: 12106224]

Friauf E, McConnell SK, Shatz CJ. Functional synaptic circuits in the subplate during fetal and early postnatal development of cat visual cortex. J Neurosci. 1990; 10:2601-2613. [PubMed: 2388080]

Godement P, Saillour P, Imbert M. Thalamic afferents to the visual cortex in congenitally anophthalmic mice. Neurosci Lett. 1979; 13:271-278. [PubMed: 530479]

Halloran MC, Kalil K. Dynamic behaviors of growth cones extending in the corpus callosum of living cortical brain slices observed with video microscopy. J Neurosci. 1994; 14:2161-2177. [PubMed: 8158263]

Harris WA, Holt CE, Bonhoeffer F. Retinal axons with and without their somata, growing to and arborizing in the tectum of Xenopus embryos: a time-lapse video study of single fibres in vivo. Development. 1987; 101:123-133. [PubMed: 3449363]

Hedin-Pereira C, Lent R, Jhaveri S. Morphogenesis of callosal arbors in the parietal cortex of hamsters. Cereb Cortex. 1999; 9:50-64. [PubMed: 10022495]

Hogan D, Berman NE. Growth cone morphology, axon trajectory and branching patterns in the neonatal rat corpus callosum. Brain Res Dev Brain Res. 1990; 53:283-287.

Hua JY, Smear MC, Baier H, Smith SJ. Regulation of axon growth in vivo by activity-based competition. Nature. 2005; 21:1022-1026. [PubMed: 15846347]

Ignacio MPD, Kimm EJ, Kageyama GH, Yu J, Robertson RT. Postnatal migration of neurons and formation of laminae in rat cerebral cortex. Anat Embryol. 1995; 191:89-100. [PubMed: 7726396]

Innocenti GM, Price DJ. Exuberance in the development of cortical networks. Nat Rev Neurosci. 2005; 6:955-965. [PubMed: 16288299]

Innocenti GM, Fiore L, Caminiti R. Exuberant projection into the corpus callosum from the visual cortex of newborn cats. Neurosci Lett. 1977; 4:237-242. [PubMed: 19604951]

Kageyama GH, Robertson RT. Development of geniculocortical projections to visual cortex in rat: evidence early ingrowth and synaptogenesis. J Comp Neurol. 1993; 335:123-148. [PubMed: 7691903]

Kanold PO, Prakash K, Reid CR, Shatz CJ. Role of sub-plate neurons in functional maturation of visual cortical columns. Science. 2003; 301:521-525. [PubMed: 12881571]

Katz LC, Shatz CJ. Synaptic activity and the construction of cortical circuits. Science. 1996; 274:1133-1138. [PubMed: 8895456]

Kennedy H, Salin P, Bullier J, Horsburgh G. Topography of developing thalamic and cortical pathways in the visual system of the cat. J Comp Neurol. 1994; 348:298-319. [PubMed: 7814694]

Knott GW, Holtmaat A, Wilbrecht L, Welker E, Svoboda K. Spine growth precedes synapse formation in the adult neocortex in vivo. Nat Neurosci. 2006; 9:1117-1124. [PubMed: 16892056]

Lendvai B, Stern EA, Chen B, Svoboda K. Experience-dependent plasticity of dendritic spines in the developing rat barrel cortex in vivo. Nature. 2000; 404:876-881. [PubMed: 10786794]

Majewska A, Sur M. Motility of dendritic spines in visual cortex in vivo: changes during the critical period and effects of visual deprivation. Proc Natl Acad Sci U S A. 2003; 100:16024-16029. [PubMed: 14663137]

McLaughlin T, Torborg CL, Feller MB. Retinotopic map refinement requires spontaneous retinal waves during a brief period of development. Neuron. 2003; 40:1147-1160. [PubMed: 14687549]

Montero VM, Brugge JF, Beitel RE. Relation of the visual field to the lateral geniculate body of the albino rat. J Neurophysiol. 1968; 31:221-136. [PubMed: 5687382]

Montero VM, Rojas A, Torrealba F. Retinotopic organization of striate and peristriate visual cortex in the albino rat. Brain Res. 1973; 53:197-201. [PubMed: 4697246] 
Naegele JR, Jhaveri S, Schneider GE. Sharpening of topographical projections and maturation of geniculocortical axon arbors in the hamster. J Comp Neurol. 1988; 277:593-607. [PubMed: 2463293]

Norris CR, Kalil K. Guidance of callosal axons by radial glia in the developing cerebral cortex. J Neurosci. 1991; 11:3481-3492. [PubMed: 1941093]

Norris CR, Kalil K. Development of callosal connections in the sensorimotor cortex of the hamster. J Comp Neurol. 1992; 326:121-132. [PubMed: 1479065]

Olavarria JF, Hiroi R. Retinal influences specify corticocortical maps by postnatal day six in rats and mice. J Comp Neurol. 2003; 459:156-172. [PubMed: 12640667]

Olavarria J, Montero VM. Reciprocal connections between the striate cortex and extrastriate cortical visual areas in the rat. Brain Res. 1981; 217:358-363. [PubMed: 7248793]

Olavarria J, Montero VM. Relation of callosal and striate-extrastriate cortical connections in the rat: morphological definition of extrastriate visual areas. Exp Brain Res. 1984; 54:240-252. [PubMed: 6723844]

Olavarria JF, Safaeian P. Development of callosal topography in visual cortex of normal and enucleated rats. J Comp Neurol. 2006; 496:495-512. [PubMed: 16572463]

Olavarria J, Van Sluyters RC. Organization and postnatal development of callosal connections in the visual cortex of the rat. J Comp Neurol. 1985; 239:1-26. [PubMed: 4044927]

Olavarria, JF.; Ruthazer, ES.; Lasiene, J.; Cline, HT. Time-lapse confocal analysis reveals highly dynamic changes in the development of axonal projections from striate to extrastriate visual cortex in the rat. Washington, DC: Society for Neuroscience; 2003. Program No.35.11.2003 Abstract Viewer/Itinerary Planner

Olavarria, JF.; Ruthazer, ES.; Fujiike, Y.; Bachleda, AR. Emergence of striate to extrastriate projections in the rat correlates with a reduction in the number of branch buds in parental axons. Washington, DC: Society for Neuroscience; 2006. Program No. 518.16 2006 Abstract Viewer/ Itinerary Planner

Olavarria JF, van Brederode JFM, Spain WJ. Retinal influences induce bidirectional changes in the kinetics of N-methyl-D-aspartate receptor-mediated responses in striate cortex cells during postnatal development. Neuroscience. 2007; 148:683-699. [PubMed: 17706364]

O'Rourke NA, Cline HT, Fraser SE. Rapid remodeling of retinal arbors in the tectum with and without blockade of synaptic transmission. Neuron. 1994; 12:921-934. [PubMed: 8161460]

Portera-Cailliau C, Weimer RM, De Paola V, Caroni P, Svoboda K. Diverse modes of axon elaboration in the developing neocortex. PLoS Biol. 2005; 3:e272. [PubMed: 16026180]

Ruthazer ES, Cline HT. Multiphoton imaging of neurons in living tissue: acquisition and analysis of time-lapse morphological data. Real-Time Imag. 2002; 8:175-188.

Ruthazer ES, Akerman CJ, Cline HT. Control of axon dynamics by correlated activity in vivo. Science. 2003; 301:66-70. [PubMed: 12843386]

Sato M, Lopez-Mascaraque L, Heffner CD, O'Leary DD. Action of a diffusible target-derived chemoattractant on cortical axon branch induction and directed growth. Neuron. 1994; 13:791803. [PubMed: 7946329]

Simon DK, O'Leary DDM. Development of topographic order in the mammalian retinocollicular projection. J Neurosci. 1992; 12:1212-1232. [PubMed: 1313491]

Sugiyama S, Di Nardo AA, Aizawa S, Matsuo I, Volvovitch M, Prochiantz A, Hensch TK. Experience-dependent transfer of Otx 2 homeoprotein into the visual cortex activates postnatal plasticity. Cell. 2008; 134:508-520. [PubMed: 18692473]

Tashiro A, Dunaevsky A, Blazeski R, Mason CA, Yuste R. Bidirectional regulation of hippocampal mossy fiber folopodial motility by kainate receptors: a two-step model of synaptogenesis. Neuron. 2003; 38:773-784. [PubMed: 12797961]

Warton SS, Dyson SE, Harvey AR. Visual thalamocortical projections in normal and enucleated rats: HRP and fluorescent dye studies. Exp Neurol. 1988; 100:23-39. [PubMed: 3350091]

Wise SP, Jones EG. The organization and postnatal development of the commissural projection of the rat somatic sensory cortex. J Comp Neurol. 1976; 168:313-344. [PubMed: 950383] 


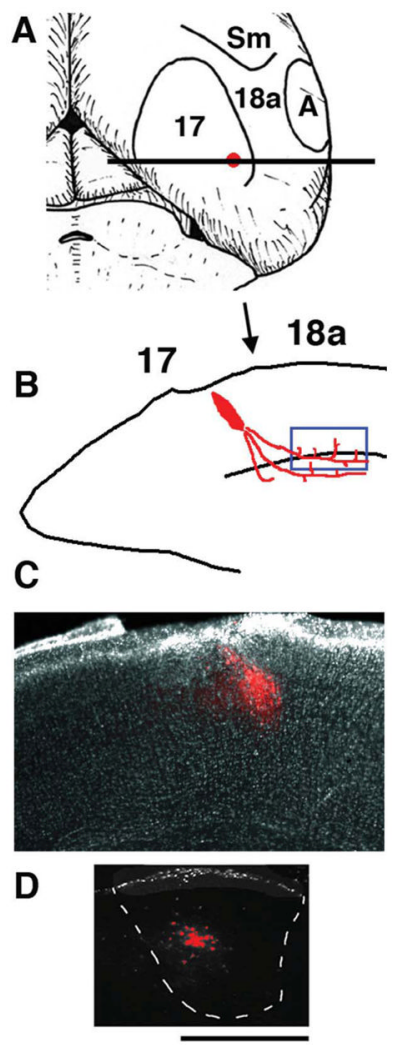

Figure 1.

Tracer injections into area 17 to reveal anterogradely labeled axons projecting from area 17 to ipsilateral area 18a. Medial is to the left. A: Diagram of top view of right hemisphere showing areas 17 and $18 \mathrm{a}$ and approximate location of the intra-cortical injection of anterogradely transported fluorescent tracers dextran Alexa into area 17. B: Diagram of coronal tissue section taken at the level of the horizontal bar in A illustrating the tracer injection in area 17 and the location of the labeled fibers in area 18a analyzed with timelapse methods (blue box near white matter). Arrow indicates presumptive 17/18a border. C: Low-power image of coronal tissue section showing an injection of Alexa 594 into area 17. D: Image from a coronal section showing the anterogradely labeled field observed in the ipsilateral dLGN following the Alexa 594 injection shown in C. Scale bar $=500 \mu \mathrm{m}$. 

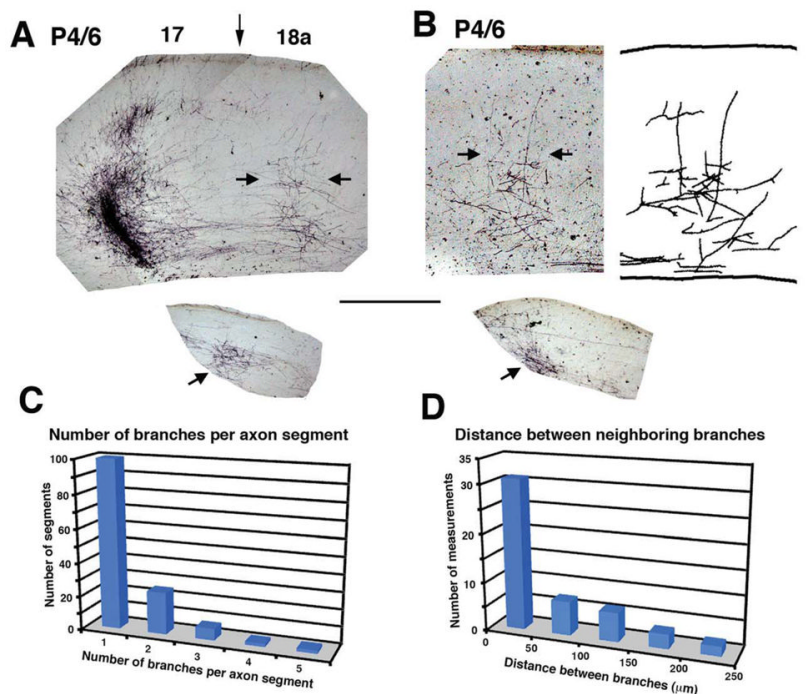

Distance between neighboring branches
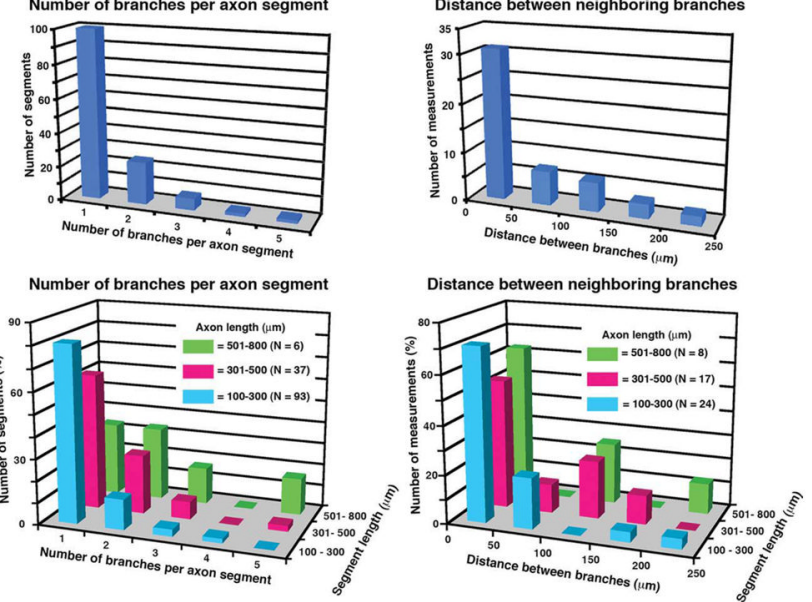

Figure 2.

Area 17-18a projections at P6. A, B: Images from coronal tissue sections from two animals illustrating the area 17-18a projections labeled following discrete intracortical injections of the anterogradely transported tracer BDA into area 17. Medial is to the left. Both animals (case L47 BN in A and case L47 FN in B) were injected with BDA at P4 and studied at P6 (P4/6). Darkly stained field to the left in A corresponds to the tracer injection, and the vertical arrow indicates approximate location of 17/18a border. The injection site is not shown in B. Labeled fibers in area 18 a accumulate in column-like fields in regions indicated by the horizontal arrows. The drawing to the right in B is a reconstruction of the labeled field from two neighboring sections. Lower insets show restricted BDA-labeled fields (indicated by arrows) in the dLGN ipsilateral to the injection sites. C: Top histogram illustrates the distribution of parental axon segments with one or more collateral branches independent of the length of the parental axon segment analyzed. Bottom histogram illustrates the distribution of parental axon segments with one or more collateral branches as a function of the length (coded by different colors) of the parental axon segment analyzed. D: Top histogram illustrates the distribution of distances between neighboring branches observed in parental axon segments with more than one branch, independent of the length of the axon segment analyzed. Bottom histogram illustrates the distribution of distances between neighboring branches in parental axon segments with more than one branch as a function of the length (coded by different colors) of the axon segment analyzed. Scale bar $=$ $500 \mu \mathrm{m}$. 


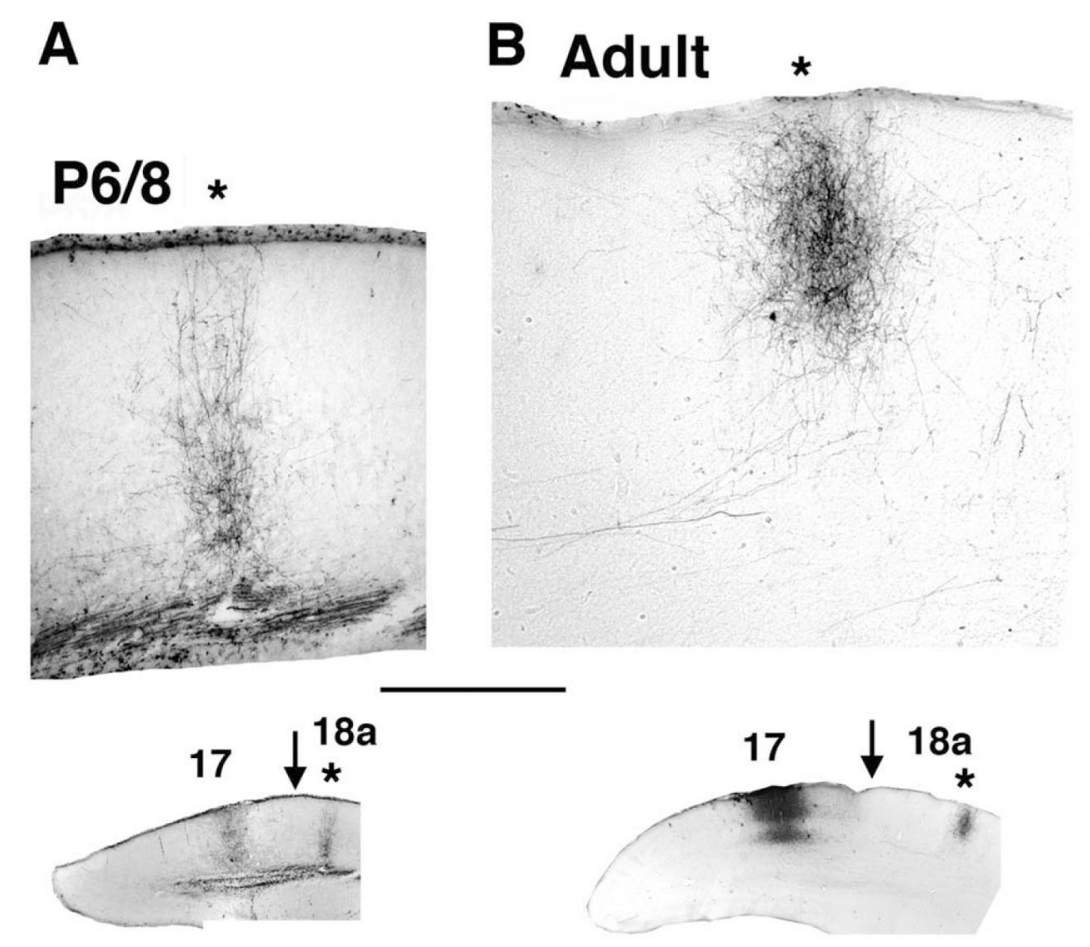

Figure 3.

Area 17-18a projections at P8 and adulthood. A, B: Images from coronal tissue sections illustrating the area 17-18a projections labeled following discrete intracortical injections of the anterogradely transported tracer BDA into area 17. Medial is to the left. A: Column-like field of BDA-labeled fibers in area 18a in an animal (case L24A) injected with BDA into area 17 at P6 and studied at P8. B: Column-like field of BDA-labeled fibers in area 18a in an adult animal (case SI4). Locations of the injection sites in area 17 and the labeled fields in area 18a (asterisks) are shown in the lower insets. Arrows in insets indicate approximate location of 17/18a border. Scale bar $=500 \mu \mathrm{m}$. 

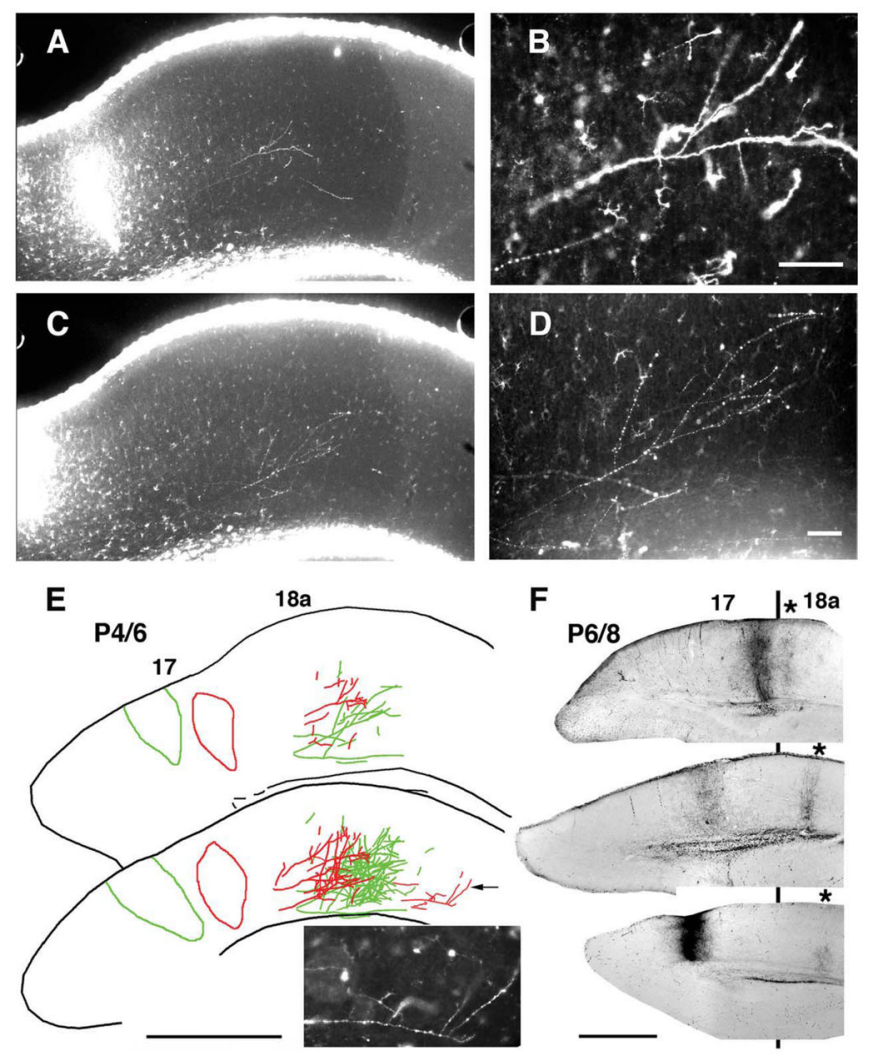

Figure 4.

Topography of striate-extrastriate projection in young rats analyzed in coronal tissue sections. Medial is to the left. A-E: Topography revealed at P6 following paired injections of two different dextran Alexa fluorescent tracers into area 17 at P4. Injections were separated by $350 \mu \mathrm{m}$ in the mediolateral direction. A, C: Low-power images illustrate tracer injection and the resulting projections in area 18a observed in the same tissue section with AlexaFluor 594 (A) and AlexaFluor 488 (C). Magnified views of fibers in area 18a labeled with each tracer are shown in $\mathrm{B}$ and $\mathrm{D}$, respectively. A drawing of data from both tracers observed in this single section is shown in the upper panel in E, and a reconstruction of the data in this section and in two additional neighboring sections is shown in the bottom panel in E. Inset shows magnified view of parental axon (indicated by arrow in drawing) giving rise to several, closely spaced interstitial branches located in a more lateral field, probably area LL (Montero et al., 1973; Olavarria et al., 1984). F: Topography of striate-extrastriate projection in animals injected with BDA at P6 and studied at P8. Coronal sections from three animals show injection of BDA into area 17 and resulting labeled field in area 18a (marked with asterisk). Black line indicates approximate location of 17/18a border. The projections illustrated are probably to presumptive extrastriate area LM (Olavarria and Montero, 1981). Data show mirror-image topography of 17 to 18a projections: as the injection site is displaced medially in area 17, the projection field in area 18a is displaced laterally (Olavarria and Montero, 1981). Scale bars $=100 \mu \mathrm{m}$ in B, D; $1.00 \mathrm{~mm}$ in E, F. 

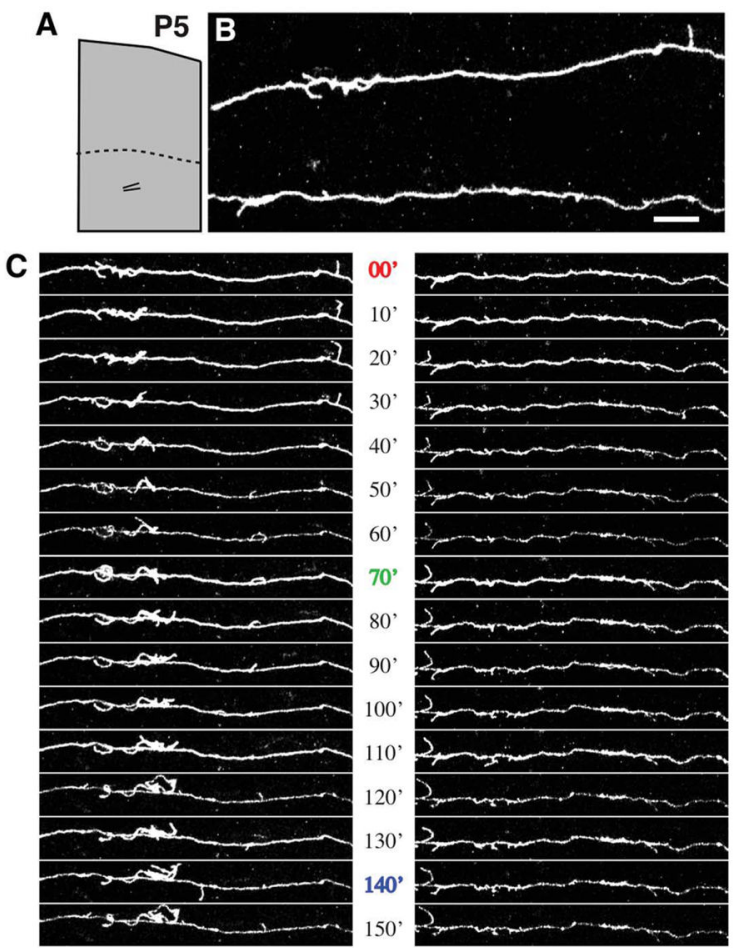

D
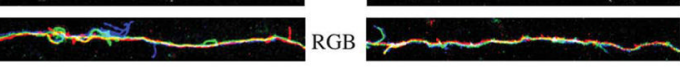

Figure 5.

Axons in the subcortical white matter extend numerous, dynamic interstital filopodia. A: At $\mathrm{P} 5$, the boundary between gray matter and white matter (dotted line) is roughly $700 \mu \mathrm{m}$ below the pial surface. B: Segments from a pair of axons running roughly parallel to the pial surface beneath area 18a were imaged by two-photon time-lapse microscopy in a living cortical slice made from P5 rat brain. The location of the pair of imaged axons is schematized in the low-magnification reconstruction in A. C: Images collected at 10-minute intervals reveal highly motile interstitial filopodia. D: Temporal overlay of three time points from series in C. Images from each time point $(0,70$, and $140 \mathrm{~min})$ are different colors, and white represents stable regions of the axon. Scale bar $=10 \mu \mathrm{m}$. 

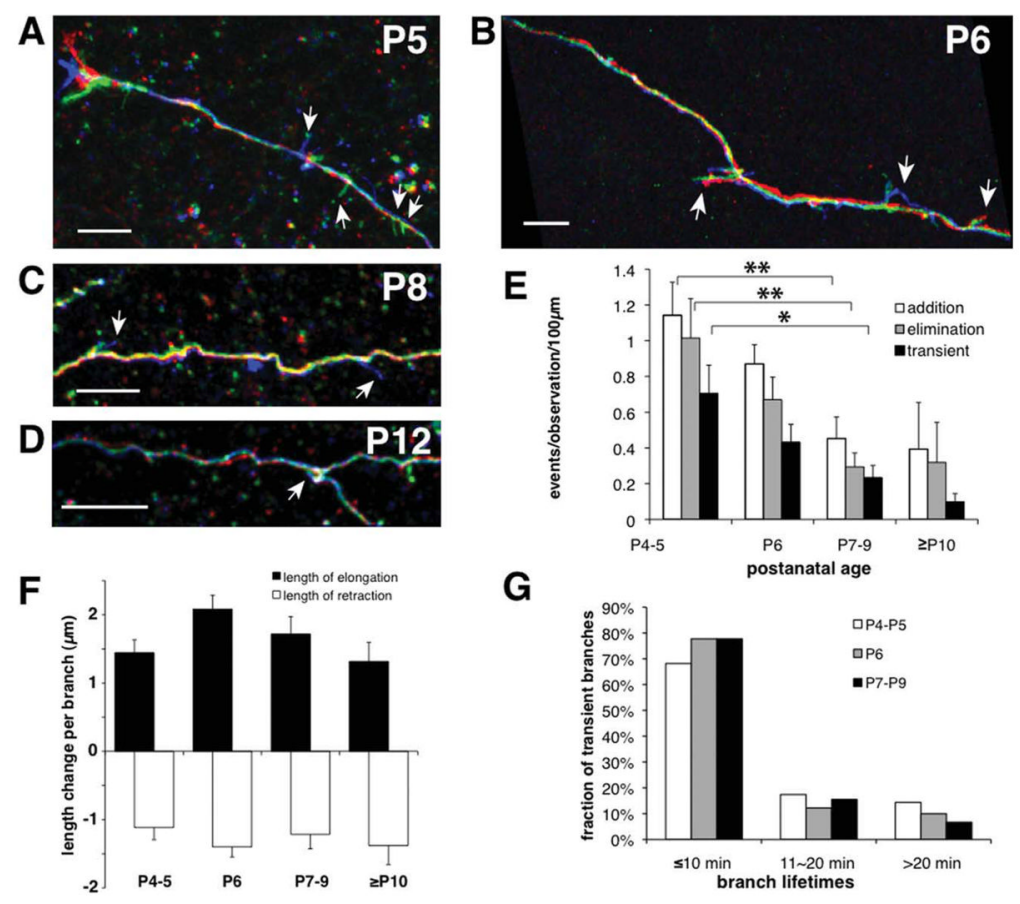

Figure 6.

Frequency of dynamic behaviors, but not growth rates or branch lifetimes, declines with age. A-D: Colorized temporal overlays show dynamic behaviors of interstitial filopodia at P5 (A), P6 (B), P8 (C), and P12 (D). Red, green, and blue correspond to early, middle, and late time points. Arrows indicate dynamic filopodia. E: Rates of branch addition and elimination as well as transient branches all decrease with age $(\mathrm{N}=18$ axons at $\mathrm{P} 4-5,30$ axons at P6, 23 axons at P7-9, 5 axons at P10-12; *P $<0.05, * * P<0.01$ ANOVA with Bonferroni posttest). F: Mean change in length of each dynamic filopodium per imaging interval (usually 10 minutes) was the same at all ages (elongating: $\mathrm{N}=336,268,208$, and 12; retracting: $\mathrm{N}=324,296,228$, and 12, respectively, for P4-5, P6, P7-9, and P10-12). G: Distribution of lifetimes of transient interstitial filopodia was the same at all ages, with the majority of transient branches present only during one image $(\mathrm{N}=143,91$, and 41 at $\mathrm{P} 4-5$, $\mathrm{P6}$, and P7-9). There were too few transient filopodia $(\mathrm{N}=3)$ in the $\mathrm{P} 10-12$ group to generate a meaningful plot. Scale bars $=10 \mu \mathrm{m}$. 

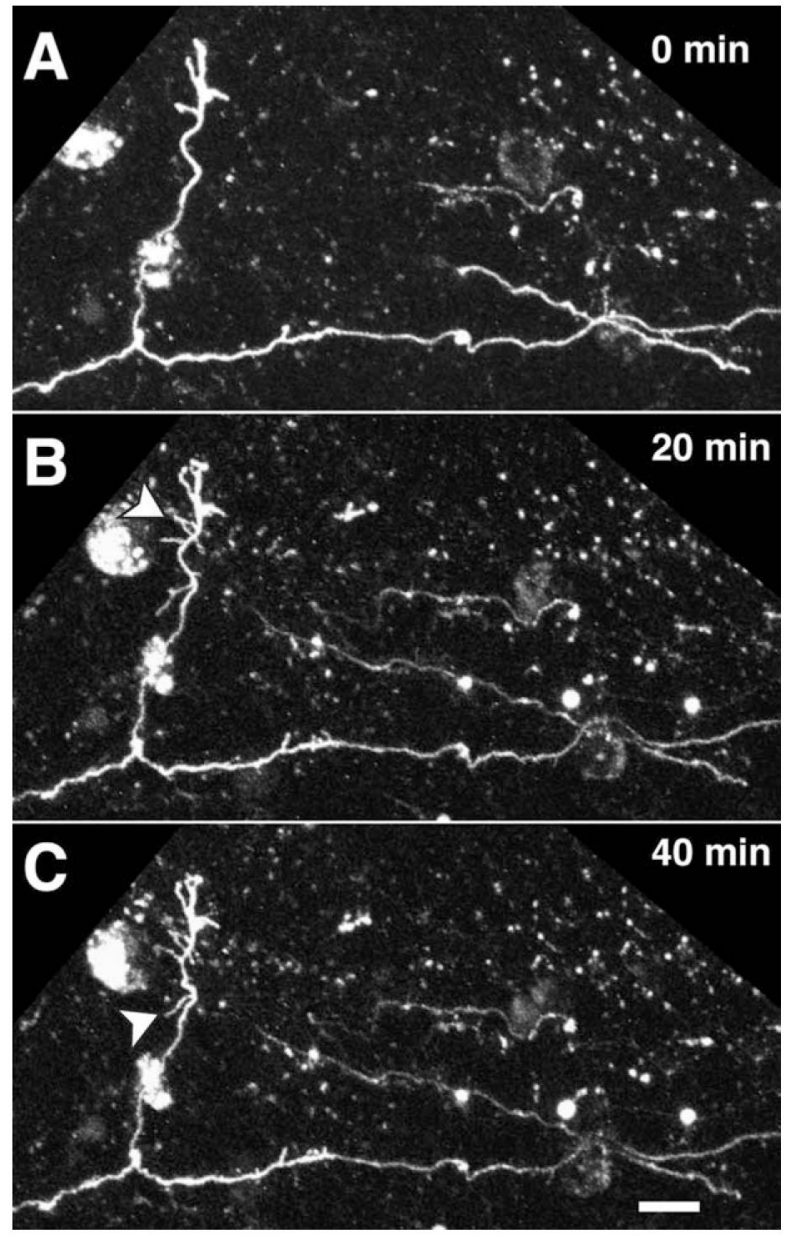

Figure 7.

Pial-directed interstitial branch formed in the white matter along a parental axon from area 17 in a P6 rat pup. A-C: Series of images showing morphological rearrangements (arrowheads) at 20-minute intervals reveals a high degree of filopodial exploration near the tip of the single large interstitial branch that has invaded cortical gray matter. Relatively little filopodial activity is observed along the parental axon at the same times. Scale bar $=10$ $\mu \mathrm{m}$. 

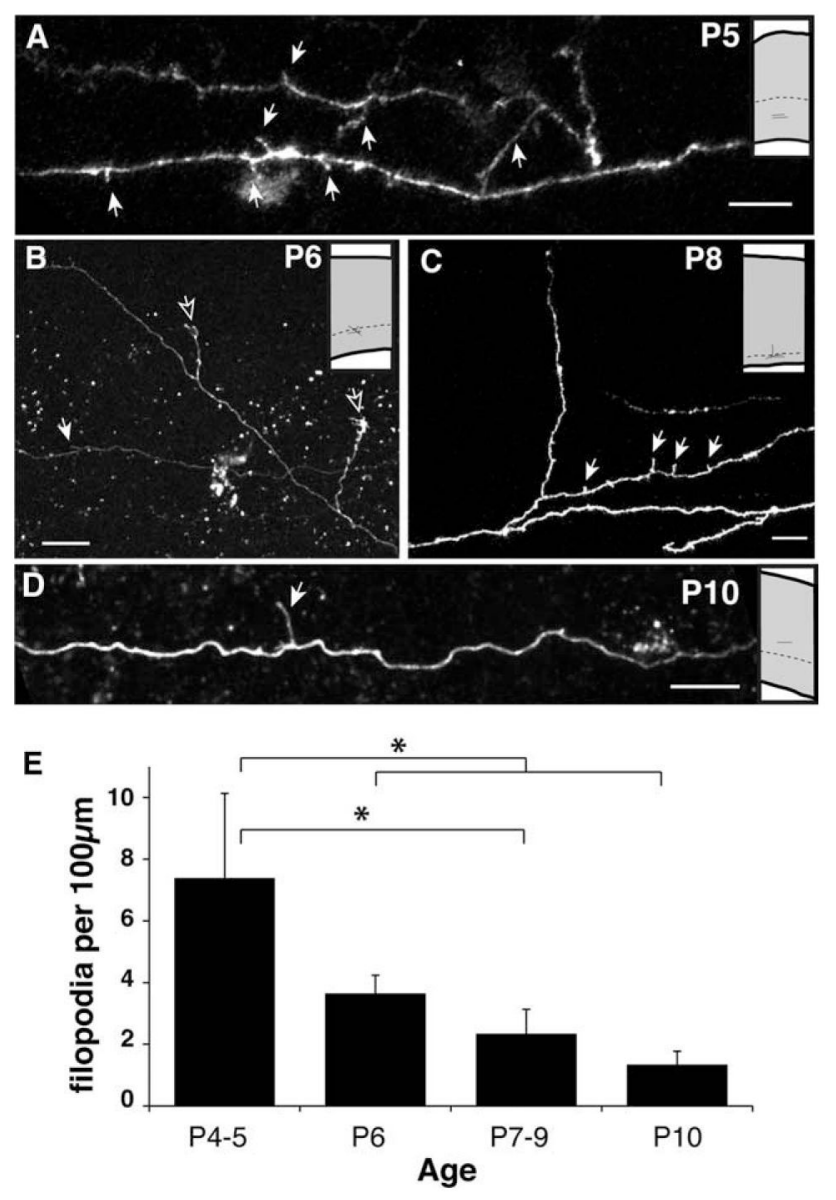

Figure 8.

Axonal filopodia in the white matter become less prevalent with age. A-D: Examples of white matter or deep layer 6 axons imaged in acute living slices at different ages. Insets show relative locations where images were collected. The presumptive white matter boundary is indicated by a dashed line. This border is found, respectively, at $700 \mu \mathrm{m}, 800$ $\mu \mathrm{m}, 900 \mu \mathrm{m}$, and 1,000 $\mu \mathrm{m}$ in P5, P6, P8, and P10 rat visual cortex (Kageyama and Robertson, 1993). Solid arrows highlight filopodia; open arrows indicate branches entering the cortical gray matter. E: Density of filopodia observed decreases with age. ${ }^{*} P<0.05$ ANOVA with Bonferroni posttest. Scale bars $=10 \mu \mathrm{m}$. 